\title{
The role of intraoperative ultrasound in gross total resection of brain mass lesions and outcome
}

\author{
Wael Abd Elrahman Ali Elmesallamy D
}

\begin{abstract}
Background: Surgical resection of brain mass lesion mandates safety and the best outcome for the patient. Objectives: The aim of this study was the evaluation of intraoperative ultrasound (IOUS) in gross total resection of brain mass lesions and patients' safety in comparison to conventional surgery.

Materials and methods: In total, 632 patients were operated for brain mass lesion resection at Neurosurgery Department, Zagazig University Hospitals, during the period from January 2011 to October 2018 and divided randomly into two groups, IOUS group and conventional group, for the detection value of IOUS in resection, safety, and outcome after 3 months follow-up.

Results: The IOUS group showed statistically significant gross total resection regardless to pathology, location, size, age, and sex in favor of IOUS use, and also, there were significantly less complications and better outcome after 3 months follow-up with the IOUS group. Significantly better outcome was found with gross total resection in total surgeries.
\end{abstract}

Conclusions: The use of IOUS during brain mass lesion surgery is safe and can assist the surgeon in gross total resection with better outcome.

Keywords: Intraoperative ultrasound, Brain mass lesions, Gross total resection

\section{Introduction}

The use of ultrasound in brain mass lesion resection is a real-time capability of this imaging. Ultrasound may provide an alternative tool to intraoperative magnetic resonance imaging (MRI) for delineating tumor tissues and improving the chances of gross total resection [1]. The purpose of brain tumor removal is maximal resection while sparing healthy tissues. The extent of resection is a key prognostic factor in survival time, functional recovery, and tumor recurrence rates [2]. The optimal results of brain lesion surgery may be achieved by maximal surgical resection without disturbance of neurological functions [3]. Due to the imprecise correlation between preoperative images, intraoperative anatomy, and also poor differentiation of some tumors from a normal tissue, substantial tumor

Correspondence: waelmesallamy@gmail.com

Neurosurgery Department, Faculty of Medicine, Zagazig University, Zagazig, Egypt volume may remain postoperatively which may lead to rapid disease recurrence. To avoid these, better delineation of normal from tumor tissue intraoperatively could improve clinical outcome as increasing chance of total resection and decreasing normal tissue damage [4]. Intraoperative imaging technology increases the extent of tumor resection and patients' outcome including survival time. MRI systems are time-consuming and of high cost. Computed tomography (CT) usually is not of choice as ionizing radiation and limited mass delineation. Several researches have demonstrated that the image quality of ultrasound has improved enough to visualize and guide tumor resection $[1,5]$. The most important disadvantage of neuronavigation is the inconsistency with preoperative images from changes of the lesion and critical anatomic structures associated with brain shift as intraoperative tumor resection or cerebrospinal fluid drainage. This creates the need for updating the preoperative image with the intraoperative image [6].
Springer Open

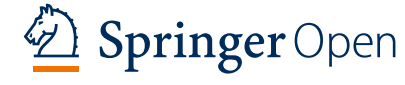

(c) The Author(s). 2019 Open Access This article is distributed under the terms of the Creative Commons Attribution 4.0 International License (http://creativecommons.org/licenses/by/4.0/), which permits unrestricted use, distribution, and reproduction in any medium, provided you give appropriate credit to the original author(s) and the source, provide a link to the Creative Commons license, and indicate if changes were made. 
Table 1 Study population criteria

\begin{tabular}{|c|c|c|c|c|c|}
\hline \multirow[t]{2}{*}{ Parameters } & \multicolumn{2}{|l|}{ IOUS group } & \multicolumn{2}{|c|}{ Conventional group } & \multirow[t]{2}{*}{$p$} \\
\hline & $N$ & $\%$ & $N$ & $\%$ & \\
\hline Number $(N)$ & 332 & 53 & 300 & 47 & 0.1 \\
\hline \multicolumn{6}{|l|}{ Age } \\
\hline$\leq 18 y$ & 84 & 25 & 76 & 25 & \\
\hline$>18 y$ & 248 & 75 & 224 & 75 & \\
\hline Range & 3 months to 70 years & & $1-70$ years & & \\
\hline Mean & 47 years & & 46 years & & 0.9 \\
\hline \multicolumn{6}{|l|}{ Sex } \\
\hline Male & 215 & 65 & 198 & 66 & 0.8 \\
\hline Female & 117 & 35 & 102 & 34 & 0.8 \\
\hline \multicolumn{6}{|l|}{ Pathology } \\
\hline Tumors & 238 & 72 & 208 & 69 & 0.3 \\
\hline Hematoma & 56 & 17 & 65 & 22 & 0.1 \\
\hline Abscess & 38 & 11 & 27 & 9 & 0.4 \\
\hline Tumor types & 238 & & 208 & & \\
\hline Glioma & 154 & 65 & 147 & 71 & 0.1 \\
\hline Metastatic & 42 & 18 & 15 & 7 & 0.03 \\
\hline Medulloblastoma & 22 & 9 & 28 & 13 & 0.07 \\
\hline Others & 20 & 8 & 18 & 9 & 0.6 \\
\hline \multicolumn{6}{|c|}{ Location to tentorium cerebelli } \\
\hline Supratentorial & 245 & 74 & 222 & 74 & \\
\hline Infratentorial & 87 & 26 & 78 & 26 & \\
\hline \multicolumn{6}{|l|}{ Location to cortex } \\
\hline Cortical, and subcortical & 96 & 29 & 100 & 33 & 0.3 \\
\hline Subcortical & 236 & 71 & 200 & 67 & 0.3 \\
\hline \multicolumn{6}{|l|}{ Maximal diameter } \\
\hline$\leq 5 \mathrm{~cm}$ & 205 & 62 & 187 & 62 & \\
\hline$>5 \mathrm{~cm}$ & 127 & 38 & 113 & 38 & \\
\hline
\end{tabular}

IOUS intraoperative ultrasound

The ultrasonography can assist the surgeon to solve the common problem of brain shift, and any tumor residual can be spotted by ultrasound and removed [7].

The aim of this study was the evaluation of intraoperative ultrasound in gross total resection of brain mass lesions and patients' safety in comparison to conventional surgery.

\section{Patients and methods}

Since 2007, the intraoperative ultrasound has been used during brain and spinal cord surgeries at Neurosurgery Department, Zagazig University Hospitals, but not routinely in all surgeries.

In total, 632 patients were operated for brain mass lesion resection at Neurosurgery Department, Zagazig University Hospitals, during the period from January
2011 to October 2018 and divided randomly into two groups: IOUS group and conventional group. All surgeries were done under general anesthesia. Ultrasound IBE-2500D, a digital scanner with endocavitary transducer 5, 6.5, and $8 \mathrm{MHZ}$ of footprint $1.8 \times 0.8 \mathrm{~cm}$ which is used in most operative works and electronic convex array transducer $2.5,3.5$, and $5 \mathrm{MHZ}$ of footprint $5 \times 1.2 \mathrm{~cm}$ which is used to examine deep details especially with large craniotomy, is known as the reverse relation between frequency and both of depth and resolution; low-frequency waves offer low image spatial resolution but can penetrate deeper as low degree of waves of attenuation. The probe was covered by a sterile glove filled with the acoustic gel. For delineating the best image spatial resolution of the brain and the mass lesion, the following factors must be 
Table 2 Extent of mass lesion resection comparison between both groups

\begin{tabular}{|c|c|c|c|c|c|c|c|c|c|c|c|c|c|}
\hline \multirow[t]{3}{*}{ Parameters } & \multicolumn{6}{|c|}{ IOUS group } & \multicolumn{6}{|c|}{ Conventional group } & \multirow[t]{3}{*}{$p$} \\
\hline & \multicolumn{2}{|c|}{ Gross total } & \multicolumn{2}{|c|}{ Subtotal } & \multicolumn{2}{|c|}{ Partial } & \multicolumn{2}{|c|}{ Gross total } & \multicolumn{2}{|c|}{ Subtotal } & \multicolumn{2}{|c|}{ Partial } & \\
\hline & $N$ & $\%$ & $N$ & $\%$ & $N$ & $\%$ & $N$ & $\%$ & $N$ & $\%$ & $N$ & $\%$ & \\
\hline Tumors & $179 / 238$ & 75 & 49 & 21 & 10 & 4 & $63 / 208$ & 30 & 107 & 51 & 38 & 18 & $<0.05$ \\
\hline Gliomas & $111 / 154$ & 72 & 35 & 23 & 8 & 6 & $33 / 147$ & 22 & 90 & 61 & 24 & 16 & \\
\hline High grades & $89 / 122$ & 73 & 27 & 22 & 6 & 7 & $21 / 107$ & 20 & 74 & 70 & 12 & 11 & \\
\hline Low grades & $22 / 32$ & 69 & 8 & 25 & 2 & 6 & $12 / 40$ & 30 & 16 & 40 & 12 & 30 & \\
\hline Metastatic & $36 / 42$ & 86 & 4 & 10 & 2 & 5 & $6 / 15$ & 40 & 4 & 27 & 5 & 33 & \\
\hline Medulloblastoma & $18 / 22$ & 82 & 4 & 18 & & & $15 / 28$ & 54 & 7 & 25 & 6 & 21 & \\
\hline Others & $14 / 20$ & 70 & 6 & 30 & & & $9 / 18$ & 50 & 6 & 33 & 3 & 17 & \\
\hline Hematoma & 45 & 80 & 11 & 20 & & & 30 & 46 & 30 & 46 & 5 & 8 & 0.001 \\
\hline Abscess & 29 & 76 & 9 & 24 & & & 10 & 37 & 7 & 26 & 10 & 37 & 0.001 \\
\hline \multicolumn{14}{|l|}{ Location to tentorium } \\
\hline Supratentorial & $196 / 245$ & 80 & 40 & 16 & 9 & 4 & $73 / 222$ & 33 & 119 & 54 & 30 & 14 & 0.001 \\
\hline Infratentorial & $63 / 87$ & 72 & 23 & 26 & 1 & 1 & $30 / 78$ & 38 & 25 & 32 & 23 & 29 & \\
\hline \multicolumn{14}{|l|}{ Location to cortex } \\
\hline Cortical and subcortical & $70 / 96$ & 73 & 23 & 24 & 3 & 3 & $43 / 100$ & 43 & 44 & 44 & 13 & 13 & 0.001 \\
\hline Subcortical & $189 / 236$ & 80 & 40 & 17 & 7 & 3 & $60 / 200$ & 30 & 100 & 50 & 40 & 20 & \\
\hline \multicolumn{14}{|l|}{ Maximal diameter } \\
\hline$\leq 5 \mathrm{~cm}$ & $180 / 205$ & 88 & 21 & 10 & 4 & 2 & $80 / 187$ & 43 & 92 & 49 & 15 & 8 & 0.001 \\
\hline$>5 \mathrm{~cm}$ & $79 / 127$ & 62 & 42 & 33 & 6 & 5 & $23 / 113$ & 20 & 52 & 46 & 38 & 34 & \\
\hline \multicolumn{14}{|l|}{ Age } \\
\hline$\leq 18$ years & $63 / 84$ & 75 & 16 & 19 & 5 & 6 & $36 / 76$ & 47 & 27 & 36 & 13 & 17 & 0.001 \\
\hline$>18$ years & $196 / 248$ & 79 & 47 & 19 & 5 & 2 & $67 / 224$ & 30 & 117 & 52 & 40 & 18 & \\
\hline \multicolumn{14}{|l|}{ Sex } \\
\hline Male & $170 / 215$ & 79 & 42 & 20 & 3 & 1 & $73 / 198$ & 37 & 80 & 40 & 45 & 23 & 0.001 \\
\hline Female & $89 / 117$ & 76 & 21 & 18 & 7 & 6 & $30 / 102$ & 29 & 64 & 63 & 8 & 8 & \\
\hline
\end{tabular}

IOUS intraoperative ultrasound

Table 3 Postoperative complications and fate at the third month

\begin{tabular}{|c|c|c|c|c|c|c|c|}
\hline \multirow[t]{2}{*}{ Parameters } & \multicolumn{3}{|c|}{ IOUS group } & \multicolumn{3}{|c|}{ Conventional group } & \multirow[t]{2}{*}{$p$} \\
\hline & $\bar{N}$ & $\%$ & Improvement, \% & $\bar{N}$ & $\%$ & Improvement, $\%$ & \\
\hline Operative death & 3 & 1 & 0 & 12 & 4 & 0 & $<0.05$ \\
\hline Motor weakness & 15 & 5 & 87 & 32 & 11 & 31 & \\
\hline Dysphasia & 6 & 2 & 100 & 18 & 6 & 33 & \\
\hline Decrease consciousness & 12 & 4 & 75 & 20 & 7 & 40 & \\
\hline CSF leak & 5 & 2 & 100 & 3 & 1 & 100 & \\
\hline Wound infection & 3 & 1 & 100 & 3 & 1 & 100 & \\
\hline Excessive brain edema & 3 & 1 & 0 & 12 & 4 & 0 & \\
\hline Mass bed hematoma & 4 & 1 & 100 & 12 & 4 & 50 & \\
\hline Number of patients with complications & 22 & 7 & 77 & 63 & 21 & 46 & \\
\hline
\end{tabular}


Table 4 Patients' outcome at postoperative third month regarding IOUS use

\begin{tabular}{|c|c|c|c|c|c|}
\hline \multirow[t]{2}{*}{ Parameter } & \multicolumn{2}{|c|}{ IOUS group } & \multicolumn{2}{|c|}{ Conventional group } & \multirow[t]{2}{*}{$p$} \\
\hline & $N$ & $\%$ & $N$ & $\%$ & \\
\hline Karnofsky improvement & 269 & 81 & 120 & 40 & 0.001 \\
\hline \multicolumn{6}{|l|}{ Functional Karnofsky outcome } \\
\hline Independent (80-100) & 252 & 76 & 171 & 57 & 0.03 \\
\hline Semi-dependent (60-70) & 55 & 17 & 96 & 32 & 0.02 \\
\hline Dependent $(\leq 50)$ & 25 & 8 & 33 & 11 & 0.07 \\
\hline Death (0) & 3 & 1 & 12 & 4 & 0.01 \\
\hline Postoperative complication improvement & $17 / 22$ & 77 & $29 / 63$ & 46 & 0.02 \\
\hline
\end{tabular}

IOUS intraoperative ultrasound

applied: The first factor is the position of the patient's head must allow the lesion and the resection cavity to be upward to permit saline to stay in the resection cavity and prevent air artifact. In posterior fossa surgery in sitting position, elongated glove finger gel pad technique was used to fill the surgical cavity. The second factor is selecting the proper ultrasound probe regarding size and frequencies. The third factor is the gel connection without air bubbles inside the glove. The fourth factor is adjusting the scanner brightness, depth, gain compensation, focus, and frequency for best images. The fifth factor is cottonoid and spatula should be removed, and blood washing by saline during imaging.

The ultrasound was used before dural opening for delineation of the mass lesion, after dural opening for tailoring the site and direction of surgical corridor, and during resection for determining the process of surgery. The ultrasound probe can be used to identify the best site for cortical incision, taking into account the shorter path to the middle of the lesion, and avoidance of eloquent cortex according to preoperative imaging data. In cases with remnants detected by ultrasound in the eloquent area, the operation was ended without gross total resection. The surgeon or the assistant is well trained for ultrasound usage either machine work, image reading, or tissue manipulation.
CT or MRI of the brain was done during the first $48 \mathrm{~h}$ after surgery for assessing the extent of resection. Gross total resection (GTR) was considered when no visible mass in postoperative imaging, subtotal resection (STR) when $>50 \%$ resection, and partial $(p)$ resection when less $50 \%$ resection. The calculation of mass residual in most cases was done according to the method of Bergsneider and colleagues [8], which depends on early postoperative MRI (within $48 \mathrm{~h}$ of surgery); in cases of contrastenhancing lesions, the residual was defined as enhancing axial T1 tissues after excluding spontaneously hyperintense T1 tissues, e.g., blood products identified on precontrast T1. For non-enhancing tumor regions, the residual was delineated as remaining areas of $\mathrm{T} 2$ of preoperative imaging taking into account postoperative changes.

All patients studied preoperatively by imaging, laboratory investigations, and clinically for general, and neurological status, and then after surgery for at least three months for detecting the extent of resection, and the neurological status for comparing the two groups of patients with, and without intraoperative ultrasound usage. Karnofsky [9] performance score was used to assess the condition of the patients preoperatively, and during follow up for comparison. Patients with meningiomas, recurrent tumors, or

Table 5 Patients' outcome at postoperative third month regarding the extent of resection

\begin{tabular}{|c|c|c|c|c|c|c|c|}
\hline \multirow[t]{2}{*}{ Parameter } & \multicolumn{2}{|c|}{ Gross total, $n=362$} & \multicolumn{2}{|c|}{ Subtotal, $n=207$} & \multicolumn{2}{|c|}{ Partial, $n=63$} & \multirow[t]{2}{*}{$p$} \\
\hline & $N$ & $\%$ & $N$ & $\%$ & $N$ & $\%$ & \\
\hline Karnofsky improvement & 292 & 81 & 86 & 42 & 11 & 17 & 0.001 \\
\hline \multicolumn{8}{|l|}{ Functional Karnofsky outcome } \\
\hline Independent (80-100) & 257 & 71 & 133 & 64 & 33 & 52 & \multirow[t]{4}{*}{$<0.05$} \\
\hline Semi-dependent (6-70) & 81 & 22 & 39 & 19 & 16 & 25 & \\
\hline Dependent $(\leq 50)$ & 20 & 6 & 28 & 14 & 10 & 16 & \\
\hline Death (0) & 4 & 1 & 7 & 3 & 4 & 6 & \\
\hline Postoperative complications improvement & $24 / 37$ & 65 & $7 / 33$ & 52 & $5 / 15$ & 33 & 0.01 \\
\hline
\end{tabular}




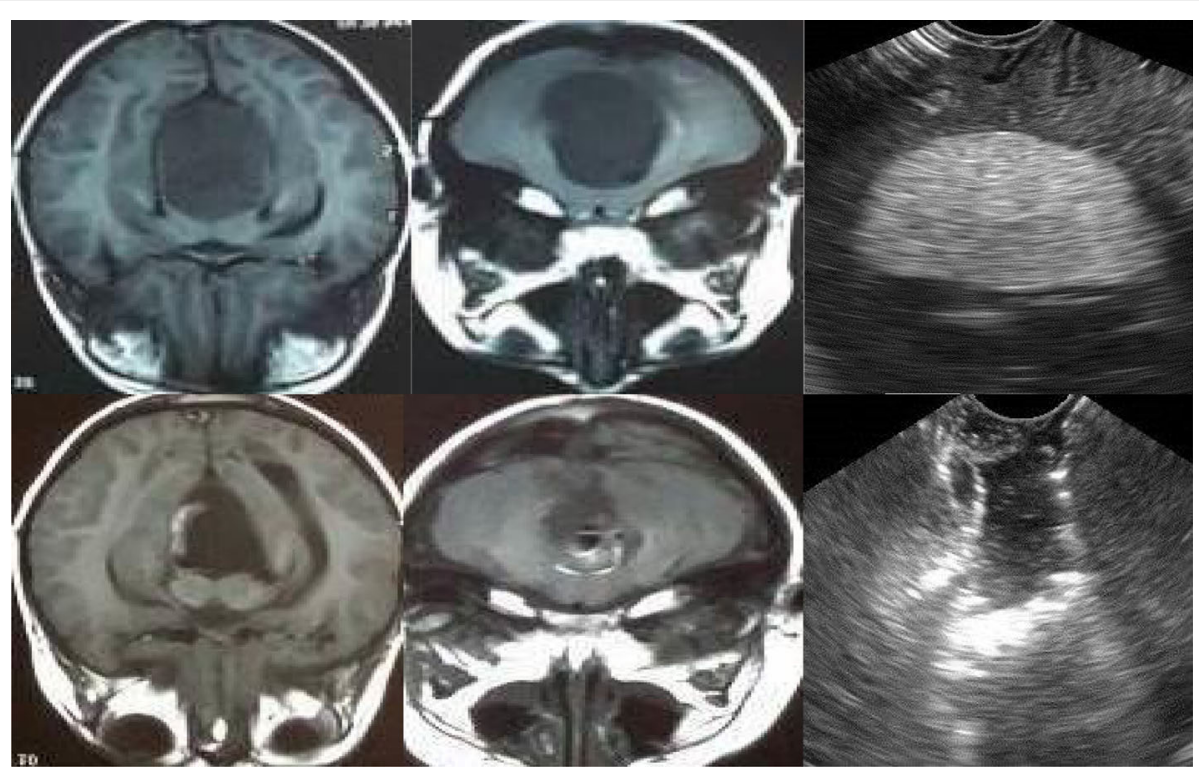

MRI: Magnetic Resonance Imaging, IOUS: Intra-Operative Ultrasound

Fig. 1 Gross total resection of posterior fossa medulloblastoma in prone position; preoperative and postoperative MRI T1 with contrast and IOUS images

incomplete data were excluded from this study. Informed consents were obtained for the procedures with approval from the Zagazig University Institutional Review Board (Zu-IRB).

The collected data were coded, processed, and analyzed using the SPSS (Statistical Package for Social Sciences) version 20 Windows (SPSS Inc., 2012-013, IBM, USA). Quantitative data was presented as number and percent. Comparison between groups was done by chi-square test. Student's $t$ test was used to compare between the two groups. $p<0.05$ was considered to be statistically significant.

\section{Results}

In this study, 632 patients were operated for brain mass lesion resection, divided randomly into two groups,

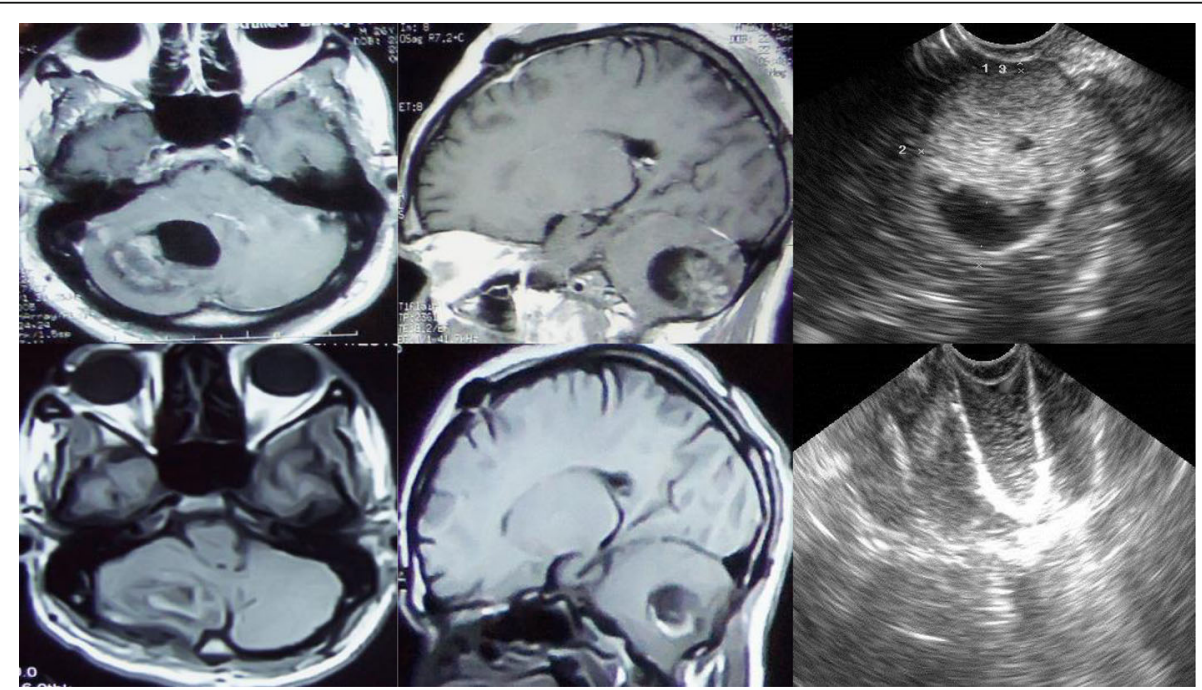

MRI: Magnetic Resonance Imaging, IOUS: Intra-Operative Ultrasound

Fig. 2 Gross total resection of posterior fossa astrocytoma grade 3 in sitting position; preoperative and postoperative MRI T1 with contrast and IOUS images. NOTE; the elongated gel filled finger glove technique in last image 


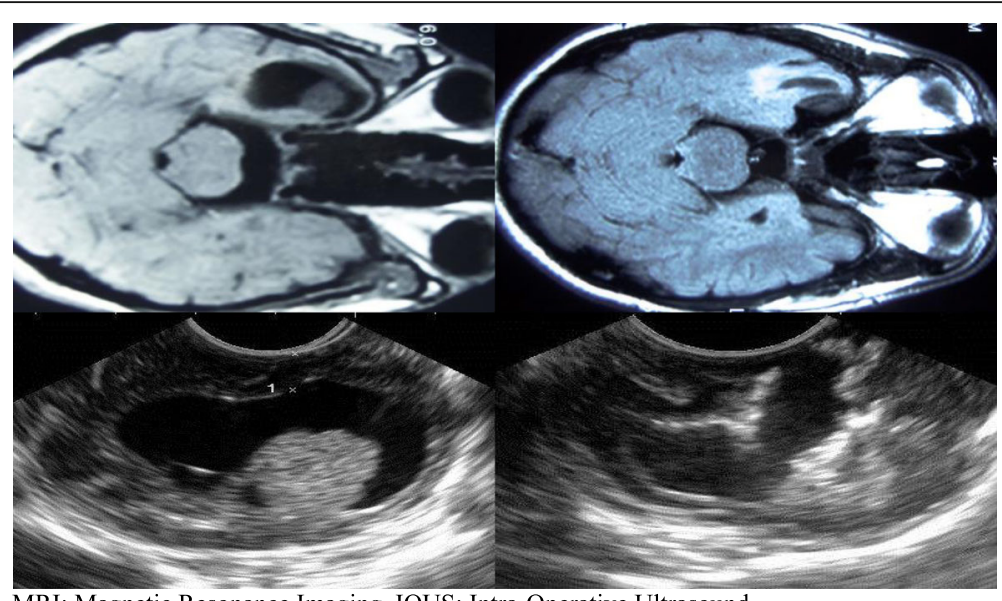

MRI: Magnetic Resonance Imaging, IOUS: Intra-Operative Ultrasound

Fig. 3 Gross total resection of astrocytoma grade 1; preoperative and postoperative MRI T1 with contrast and IOUS images

IOUS group and conventional group. The two groups' population criteria (Table 1) showed no significant difference regarding the number of patients, age, sex, pathology of lesions, location of lesions to tentorium cerebelli and cortex, and maximal mass diameter, but the IOUS group showed significantly more metastatic tumors. Table 2 showed the significant difference between the two groups regarding the extent of mass resection according to pathology, mass location, size, age, and sex in favor to IOUS use.

The main concern of the surgeon is the patients' safety during and after surgery. Tables 3 and 4 showed the role of IOUS use in patients' safety and outcomes; the IOUS group showed statistically significantly less complications and better outcome.

The value of gross total resection of brain mass lesion appeared in Table 5 as there was significantly better outcome with gross total resection in comparison to subtotal and partial resections.

\section{Discussion}

Several studies showed the benefits of intraoperative ultrasound for achieving maximal safe resection in brain tumor surgery [10].

In this study, the IOUS group showed statistically significantly better gross total resection of brain mass lesions whatever the pathology of masses, location of masses, size of masses, age of patients, and sex of patients in comparison to the conventional group. Total resections were achieved in 253/ 332 (76\%) patient with brain mass lesions, in 179/ 238 (75\%) patients with brain tumors, in 111/154 (72\%) patients with gliomas, in $73 \%$ of high-grade gliomas, $69 \%$ of low-grade gliomas, $86 \%$ of metastatic

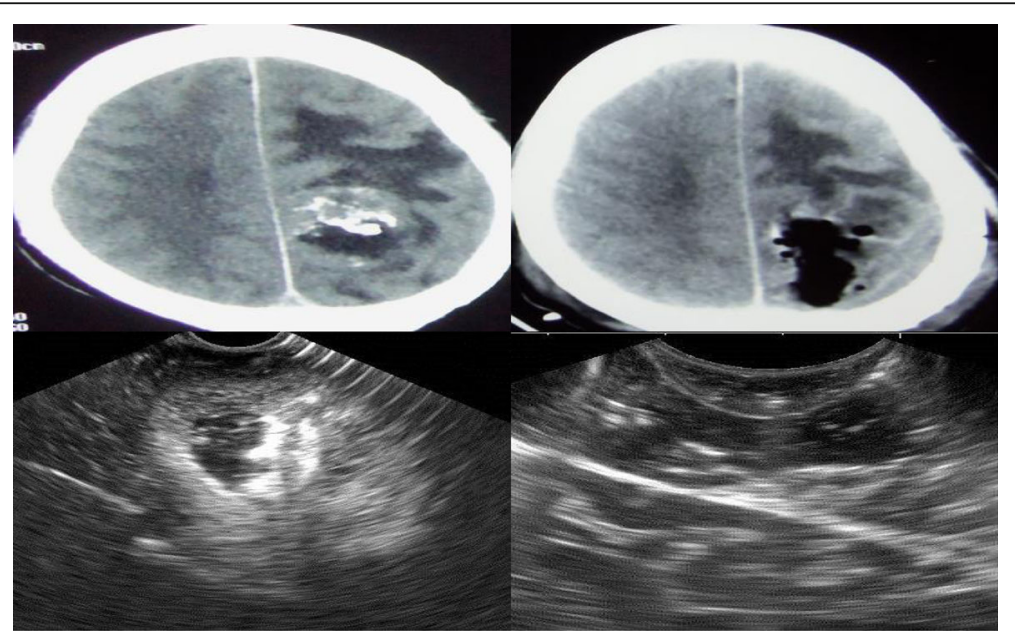

CT: Computed tomography, IOUS: Intra-Operative Ultrasound

Fig. 4 Gross total resection of calcified astrocytoma grade 2; preoperative and postoperative $C T$ with contrast and IOUS images 


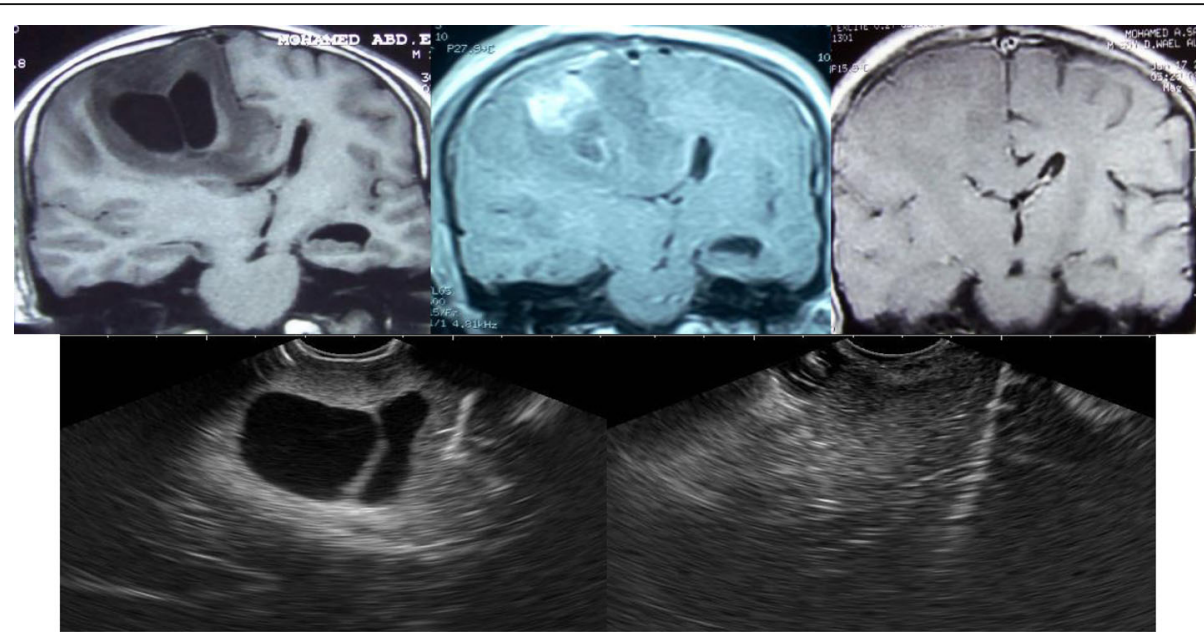

MRI: Magnetic Resonance Imaging, IOUS: Intra-Operative Ultrasound

Fig. 5 Gross total resection of pleomorphic xanthoastrocytoma grade 2, preoperative and postoperative ( early and after 3 months ) MRI T1 with contrast and IOUS images

tumors, $82 \%$ of medulloblastoma, $80 \%$ of brain hematomas, and $76 \%$ of brain abscesses in the IOUS group. By IOUS, gross total resection of infratentorial lesions ( Figs 1,2) were acheived in $72 \%$ and in $80 \%$ of supratentorial lesions (Figs 3, 4, 5, 6, 7, 8, 9 and 10).

The role of IOUS in gross total resection was addressed in many studies on brain tumors and other lesions.

Patil and colleagues [11] studied 192 patients with intracranial masses which were operated upon with IOUS.
Supratentorial lesions found in 71\%, brain abscesses in 14 cases, metastases 10 cases, glioma 83 cases, and other lesions 85 cases. Male to female ratio was 51:45, the youngest was 6 years old, and the oldest was 73 years. Gross total resection was achieved in $70 \%$, subtotal in $19 \%$, and biopsy in $11 \%$ of supratentorial lesions, while among the infratentorial group, gross total resection was achieved in $89 \%$, subtotal in $7 \%$, and biopsy in $3.6 \%$. Moiyadi and colleagues [12] reported gross total resection in 55\% of brain tumors by IOUS, and Erdogan and colleagues [13] reported 19/32 (59\%) gross total resection. Wang and
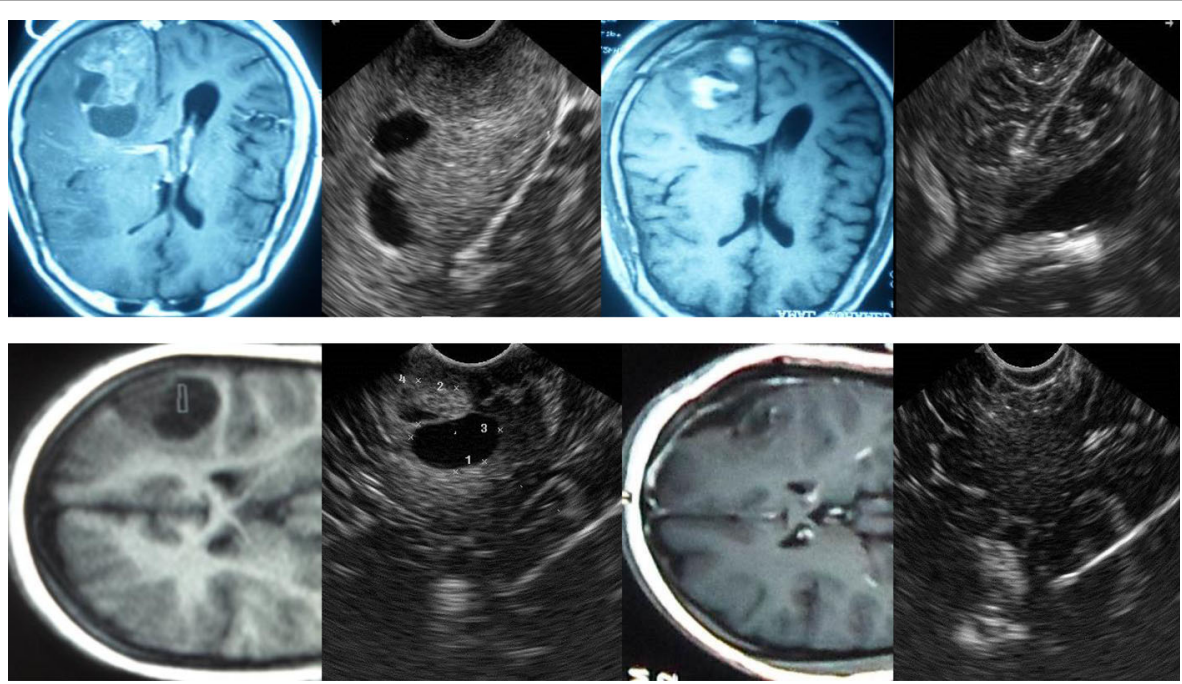

MRI: Magnetic Resonance Imaging, IOUS: Intra-Operative Ultrasound

Fig. 6 Gross total resection of astrocytoma grade 3 (TWO CASES), preoperative and postoperative MRI T1 with contrast and IOUS images. NOTE; the hyperechoic choroid plexus in both cases became more clear after tumors resection 


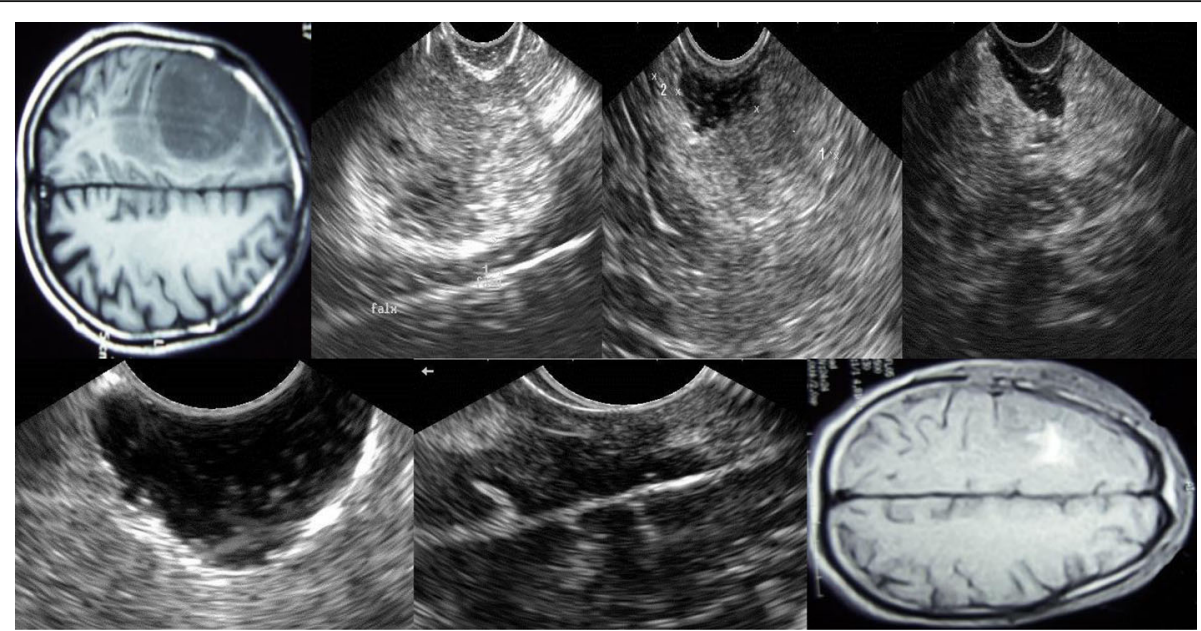

MRI: Magnetic Resonance Imaging, IOUS: Intra-Operative Ultrasound

Fig. 7 Gross total resection of glioblastoma; preoperative and postoperative MRI T1 with contrast and staged resection IOUS images

colleagues [14], in their study on IOUS use, concluded that all lesions were identified and located with accuracy $100 \%$. Total resection was achieved in $70 / 98$ (70\%) patients. IOUS facilitates total removal while protecting brain tissue and neurological symptoms improved in $80 /$ $98(82 \%)$ patients and unchanged in 18 patients. Picarelli and colleagues [15], in their study on brain metastases surgery by IOUS, the total resection was achieved in $100 \%$, and surgical morbidity and mortality were $3 \%$ and $5 \%$, respectively. In my study, the total resection by IOUS was achieved in $86 \%$ of metastatic brain tumors. Goren and colleagues [16] mentioned intracranial hemorrhage can be evacuated safely by IOUS as surgeon can assess dimensions, brain structures, and the shortest point to the clot. Tang and colleagues [17] in their study on meningioma by IOUS recorded the total resection in $19 / 20$ patients
(Simpson grades I and II). No deaths and all patients improved except one.

In this study, gross total resection of brain mass lesions in children by IOUS was 63/84 (75\%) which was statistically significantly better than the conventional group.

Studies on childhood brain lesions documented the value of IOUS. Roth and colleagues [18] had achieved gross total resection in 14/16 (88\%) patients. El Beltagy and colleagues [19] reported gross total resection in 14/ $25(56 \%)$ patients, Ulrich and colleagues [20] reported $82 \%$ gross total resection, and Moiyadi and colleagues [21] had achieved $80 \%$ gross total resection.

In surgeries without imaging, as many as $80 \%$ of brain tumors leave residual behind [22]. Literature indicated growing evidence of gross total resection of glioma by IOUS [23].

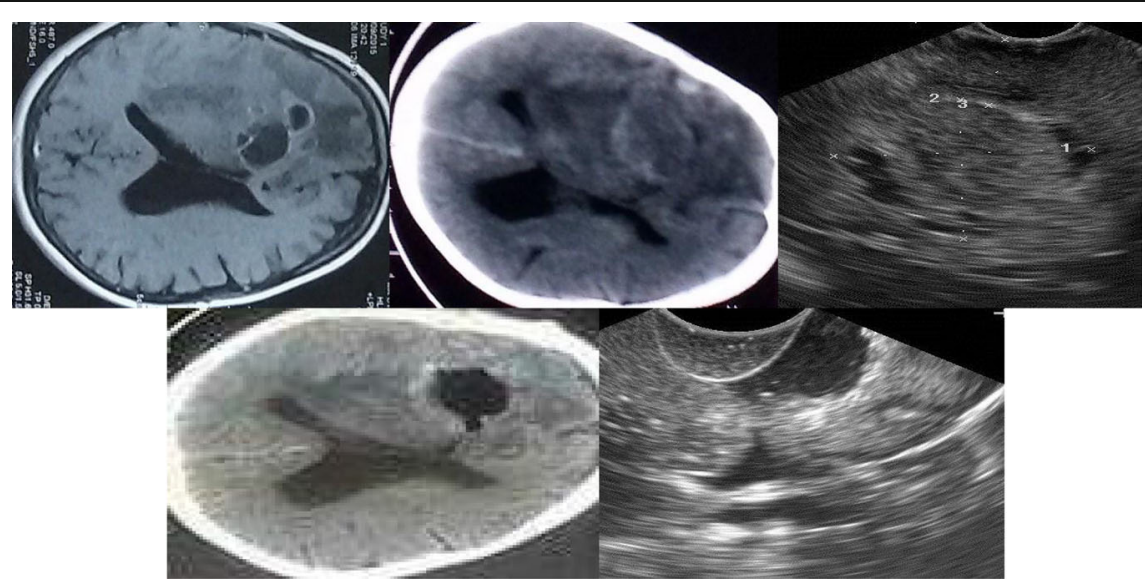

CT: Computed Tomography, MRI: Magnetic Resonance Imaging, IOUS: Intra-Operative Ultrasound

Fig. 8 Gross total resection of glioblastoma; preoperative (MRI T1 with contrast, $C T$ with contrast), postoperative $C T$ with contrast and IOUS images 

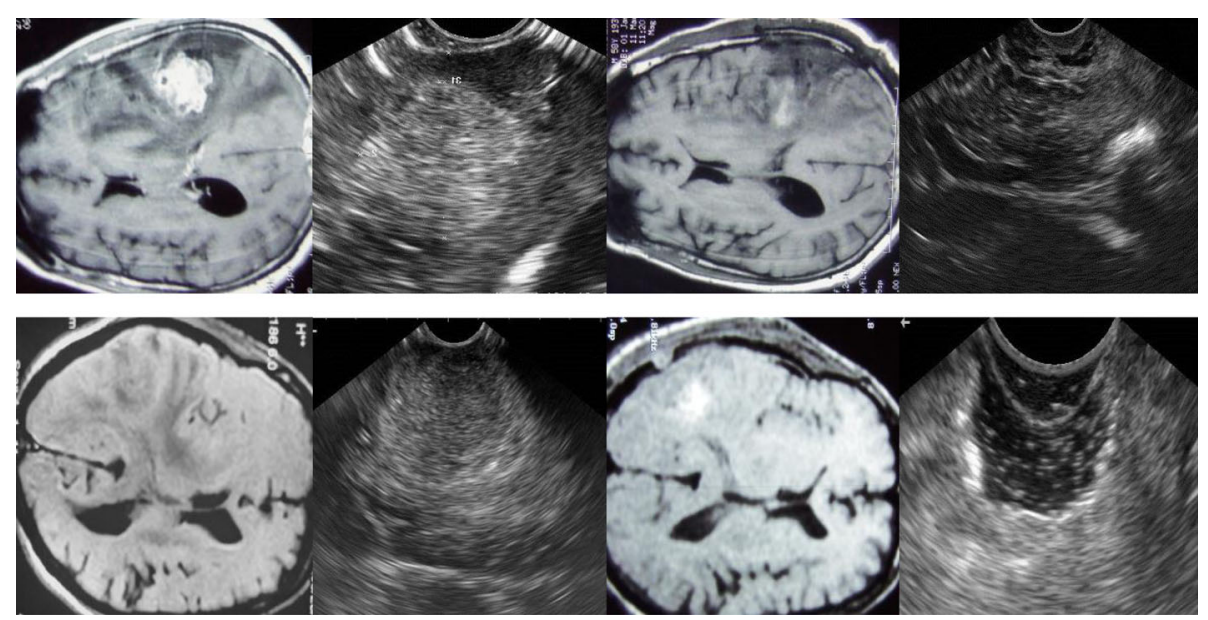

MRI: Magnetic Resonance Imaging, IOUS: Intra-Operative Ultrasound

Fig. 9 Gross total resection of metastases (TWO CASES); preoperative and postoperative MRI T1 with contrast and IOUS images

Studies on intraoperative neuronavigator, CT, MRI, 5 ALA (aminolevulinic acid) addressed great fallacies which had been avoided with IOUS as brain shift during neuronavigation, radiation exposure with $\mathrm{CT}$, high cost and long operative time of MRI, and inability of 5 ALA to stain low-grade tumors [13, 24, 25]. Roder and colleagues [26] in their study on 117 patients with brain tumors showed the total resection in 74\% with intraoperative MRI, 46\% with 5 ALA, and $13 \%$ with conventional surgery. In my study, gross total resections of brain tumors were achieved in $30 \%$ with conventional surgery. Mahboob and Eljamel [27] stated that literature review demonstrated gross total resection of glioma by neuronavigator in $31-36 \%$, by 5 ALA in $69.1 \%$, by intraoperative MRI in $70 \%$, and by intraoperative ultrasound in $73.4 \%$. Belsuzarri and colleagues [24] mentioned gross total resection increased from 36\% to $65 \%$ by using 5 ALA with glioblastoma but was useless with low-grade glioma as low vascularity of such tumors affects 5 ALA staining.

Regarding postoperative complications in this study, operative mortality in the first postoperative month was 15/ $632(2.4 \%), 3(1 \%)$ in IOUS group and $12(4 \%)$ in the conventional group. The IOUS group showed statistically significantly less complication than the conventional group. Also, there were statistically significantly better outcome 3 months after surgery in the IOUS group as shown by postoperative Karnofsky score improvement, Karnofsky functional outcome, and postoperative complication improvement in comparison to the conventional group.

Moiyadi and colleagues [21], in their study on IOUS, concluded that the extent of resection is a great prognostic marker and IOUS is a cost-effective alternative to intraoperative MRI. They recorded postoperative morbidity in only one case (1/20 patients $5 \%)$ in their study on 16 supratentorial and 4 infratentorial tumors in children (5-18 years old) and four patients showed improvement in the early postoperative period. Wang and colleagues [28] studied on small subcortical lesions including tumors, abscesses, and other lesion, they completely resected all lesions by IOUS, and all original symptoms significantly alleviated. Wang and colleagues [29] studied on 113 lesions (cranial and spinal); they stated that no IOUS complications and ultrasound



Fig. 10 Gross total resection of brain abscess; preoperative and postoperative MRI T1 with contrast and IOUS 
ensure safety by minimizing injury to neural tissues and shortening the time of surgery. Bernstein and colleagues [30] stated that ultrasonography leads to a safe and wider resection. Cheon [31] stated that the goal of cerebral glioma removal is not only maximal but also safe removal which was achieved by IOUS. Wang and colleagues [14] reported that IOUS can facilitate total lesion resection while protecting neurological function, reduce complication, and prevent mechanical injury to intracerebral blood vessels. The extent of resection is associated with survival $[18,31,32]$.

\section{Conclusion}

Brain surgeries aim to eliminate the pathological process without damage to brain tissues. The neurosurgeon reviews and assesses preoperative diagnostic information and intraoperative tools to make a decision including orientation and delineation of the pathological mass throughout the surgery. Intraoperative ultrasound is an available cheap tool which provides intraoperative safety and confidence to the surgeon for achieving total brain mass lesions resection. This study encourages to use IOUS.

\section{Abbreviations}

ALA: Aminolevulinic acid; CT: Computed tomography; GTR: Gross total resection; IOUS: Intraoperative ultrasound; MRI: Magnetic resonance imaging; P: Partial; STR: Sub-total resection

\section{Acknowledgements}

It is lucky to work with the neurosurgery team at Zagazig University Hospital.

\section{Authors' contributions}

The author contributed to the study conception, design, most of the surgical works, data collection, and drafting the manuscript. The author read and approved the final manuscript.

\section{Funding}

All patients operated at Zagazig university hospitals neurosurgery department for free.

\section{Availability of data and materials}

All data that support the findings of this study are available from the neurosurgery department Zagazig University Hospital. Data are however available from the author when requested with permission.

\section{Ethics approval and consent to participate}

A research committee approval has been granted for this study by the medical ethics committee, Faculty of Medicine, Zagazig university at 5/1/ 2012. Informed consent according to the criteria set by the local research ethics committee in our center obtained in writing before surgery. If consent could not be obtained because the patient was in a coma or young age (< 16 years), consent was obtained from the legal guardian.

\section{Consent for publication}

Informed consents were obtained for all patients and no personal data included in this study.

\section{Competing interests}

The author declares that he/she has no competing interests.
Received: 17 March 2019 Accepted: 6 September 2019

Published online: 28 November 2019

\section{References}

1. Unsgaard G, Ommendal S, Muller T, Gronningsaeter A, Hernes TAN. Neuronavigation by intraoperative three-dimensional ultrasound: initial experience during brain tumor resection. Neurosurgery. 2002;50(4): 804-12.

2. Almenawer SA, Badhiwala JH, Alhazzani W, Greenspoon J, Farrokhyar F, Yarascavitch B, et al. Biopsy versus partial versus gross total resection in older patients with high-grade glioma: a systematic review and metaanalysis. Neuro Oncol. 2015;17(6):868-81.

3. Elserry $\mathrm{TH}$, Anwer $\mathrm{H}$, Radwan HA. Introduction of vaginal probe for intraoperative ultrasound of intra-axial brain lesions. Egyp J Neurosurg. 2013; 28(4):5-12.

4. Zhang ZZ, Shield LBE, Sun DA, Zhang YP, Hunt MA, Christopher BS. The art of intraoperative glioma identification. Front Oncol. 2015;5(175):1-7.

5. Gronningsaeter A, Kleven A, Ommedal S, Aarseth TE, Lie T, Lindseth F, Lango T, Unsgaard G. Sono Wand, an ultrasound-based neuronavigation system. Neurosurgery. 2000;47(6):1373-80.

6. Tümtürk A, Kucuk AO, Ulutabanca H, Menkü A, Gergin S, Oral S. The impact of the use of neuronavigation together with intraoperative ultrasonography in minimally invasive intracranial cavernous hemangioma surgery. Erciyes Med J. 2015;36(4):161-5. https://doi.org/10.5152/etd.2014.8462.

7. Giovani A, Brehar F, Bucur N, Martin D, Gorgan RM. Intraoperative neuronavigation integrated high resolution 3D ultrasound for brain shift and tumor resection control. Romanian Neurosurg. 2015;XXIX2:141-9.

8. Bergsneider $M$, Sehati $N$, Villablanca P, McArthur DL, Donald P. Extent of glioma resection using low-field (0.2 T) versus high-field (1.5 T) intraoperative MRI, and image-guided frameless neuronavigation. Clin Neurosurg. 2005;52:389-99.

9. Karnofsky DA, Burchenal J. The clinical evaluation of chemotherapeutic agents in cancer. New York: Columbia University Press; 1949. p. 191-205.

10. Camp S, Apostolopoulos V, Raptopoulos V, Nandi D. Objective image analysis of real-time three-dimensional intraoperative ultrasound for intrinsic brain tumor surgery. J Therapeutic Ultrasound. 2017;5:2-4.

11. Patil D, Sharma V, Tiwari VDP. Intraoperative ultrasound in intracranial space occupying lesions. World J Surg Med Radiat Oncol. 2013;8:1-5.

12. Moiyadi AV, Shetty PM, Mahajan A, Udare A, Sridhar E. Usefulness of threedimensional navigable intraoperative ultrasound in resection of brain tumors with a special emphasis on malignant glioma. Acta Neurochir (Wien). 2013;155(12):2217-25.

13. Erdogan N, Tucer B, Mavili E, Menku A, Kurtsoy A. Ultrasound guidance in intracranial tumor resection: correlation with postoperative magnetic resonance findings. Acta Radiologica. 2005;46(7):743-9.

14. Wang J, Liu X, Hou WH, Dong G, Wei Z, Zhou H, Duan YY. The relationship between intraoperative ultrasonography and pathological grade in cerebral glioma. J Int Med Res. 2008;36:1426-34.

15. Picarelli H, Oliveira ML, Bor-Seng-Shu E, Ribas ESC, Santos AM, Teixeira MJ. Intraoperative ultrasonography for presumed brain metastasis: a case series study. Arq Neuro-psiquiatr. 2012;70(10):793-8.

16. Goren O, Monteith SJ, Hadani M, Bakon M, Harnof S. Modern intraoperative imaging modalities for the vascular neurosurgeon treating intracerebral hemorrhage. Neurosurg Focus. 2013;34(5):1-13.

17. Tang $H$, Sun $H$, Xie L, Tang $Q$, Gong $Y$, Mao $Y$, Xie Q, Zheng M, Wang $D$, Zhu H, Zhu J, Feng X, Yao Z, Chen X, Zhou L. Intraoperative ultrasound assistance in resection of intracranial meningiomas. Chin J Cancer Res. 2013: 25(3):339-45

18. Roth J, Biyani N, Beni-Adani CS. Real-time neuronavigation with high-quality 3D ultrasound SonoWand in pediatric neurosurgery. Pediatr Neurosurg. 2007:43(3):185-91.

19. El Beltagy MA, Aggag M, Kamal M. Role of intraoperative ultrasound in resection of pediatric brain tumors. Childs Nerv Syst. 2010;26(9): 1189-93.

20. Ulrich NH, Burkhardt JK, Serra C, Bernays RL, Bozinov O. Resection of pediatric intra-cerebral tumors with the aid of intraoperative real-time 3-D ultrasound. Childs Nerv Syst. 2012;28(1):101-9.

21. Moiyadi AV, Shetty $P$, Degaonkar A. Resection of pediatric brain tumors: intraoperative ultrasound revisited. J Pediatr Neurosci. 2017;12(1):19-23. 
22. Kanan A, Gasson B. Brain tumor resections guided by magnetic resonance imaging. AORN J. 2003;77(3):583-9.

23. Jani K. Intraoperative imaging-guided delineation and localization of regions of surgical interest: feasibility study. Acta Univ Oul D. 2012;1147:1-100.

24. Belsuzarri $T A B$, Sangenis RMA, Araujo JFM. Brain tumor surgery: supplemental intraoperative imaging techniques and future challenges. J Cancer Metastasis Treat. 2016;2:70-9.

25. Sasatry RA, Bi WL, Pieper S, Frisken SF, Kapur T, Wells WM, Golby AJ. Application of ultrasound in the resection of brain tumors. J Neuroimaging. 2017;27(1):5-15.

26. Roder C, Bisdas S, Ebner FH, Honegger J, Naegele T, Ernemann U, Tatagiba M. Maximizing the extent of resection and survival benefit of patients in glioblastoma surgery: high-field iMRI versus conventional, and 5-ALAassisted surgery. Eur J Surg Oncol. 2014;40(3):297-304.

27. Mahboob SO, Eljamel M. Intraoperative image-guided surgery in neurooncology with specific focus on high-grade gliomas. Future Oncol. 2017; 13(26):2349-61.

28. Wang J, Duan YY, Liu X, Wang Y, Gao GD, Qin HZ, Wang L. Application of intraoperative ultrasonography for guiding microneurosurgical resection of small subcortical lesions. Korean J Radiol. 2011;12(5):541-6.

29. Wang $\mathrm{Yl}$, Yong W, Dong $\mathrm{Yl}$, Yida W. The value of intraoperative ultrasound in neurosurgery. J Med Ultrasonic. 2006;33(1):61.

30. Bernstein EM, Gulati S, Solheim O, Kvistad KA, Torp SH, Selbekk T, Unsgard G, Haberg A. Functional magnetic resonance imaging and diffusion tensor tractography incorporated into 3-dimentional ultrasound based neuronavigation system: impact on therapeutic strategies, extent of resection, and clinical outcome. Neurosurgery. 2010; 67(2):251-64.

31. Cheon JE. Intraoperative neurosonography revisited: Effective neuronavigation in pediatric neurosurgery. Ultrasonography. 2015;34(2):79-87.

32. Lam CH, Hall WA, Truwit CL, Liu H. Intraoperative MRI-guided approaches to pediatric posterior fossa tumors. Pediator Neurosurg. 2001;34:295-300.

\section{Publisher's Note}

Springer Nature remains neutral with regard to jurisdictional claims in published maps and institutional affiliations.

\section{Submit your manuscript to a SpringerOpen ${ }^{\circ}$ journal and benefit from:}

- Convenient online submission

- Rigorous peer review

- Open access: articles freely available online

High visibility within the field

- Retaining the copyright to your article

Submit your next manuscript at $\boldsymbol{\nabla}$ springeropen.com 